\title{
Teaching of physical-technical fundamentals for laser applications
}

\section{Vadim Veiko}

Vadim P. Veiko, "Teaching of physical-technical fundamentals for laser applications," Proc. SPIE 2525, 1995 International Conference on Education in Optics, (13 October 1995); doi: 10.1117/12.224040

EDIE Event: SPIE's 1995 International Symposium on Optical Science, Engineering, and Instrumentation, 1995, San Diego, CA, United States 
Teaching of physical-technical fundamentals

for laser applications

Vadim P. Veiko

Technical University

"Institute of Fine Mechanics and Optics",

14, Sablinskaya str., St.Petersburg, Russia, 197101.

\section{ABSTRACT}

The following problems are discussed: why, where, what and how to teach in the field of laser applications. The experiences of Laser Technologies department of Technical University "Institute of Fine Mechanics and Optics" (IFMO) form the basis of this paper. Information from the new Russian Federal standard for university teaching in the field of laser engineering and laser applications is presented.

\section{INTRODUCTION}

Why? - We are witnesses of the rapid progress of laser appliactions (LA). General opinion is that lasers are producing a revolution in optics. But probably the same words could be expressed now for industry and medicine and, in the near future, for communication and information processing, etc. Some new results in LA such as 3-D laser prototyping and manufacturing, possibilities in genetic engineering, and in military industry, etc. convince us of the timeliness and perspective of LA teaching. As a confirmation of the significance of this direction the separate speciality "Laser engineering and laser applications" was established by the Federal Committee of Higher Education at IFMO's initiative this year and the Russian Federal standard for university teaching approved this recommendation.

The obligatory minimum of the content for educational program from this standard which was prepared by IFMO is presented in Table 1. One can see the correlations between humanitarian and social-economy (HSE), natural sciences (NS), generally professional (GP) and special professional (SP) knowledge at this standard.

But there are many questions which should be answered before the optimal teaching system can be established. One of the first - is place of teaching - Where is it better to teach LA - at laser applications departments (in Russia - laser technologies) or at different special institutions? Probably both ways are possible. But our 15 years of experience (the experience of the Laser Technologies Department (LTD) of IFMO) is grounded in the first way.

The next question - the content of education - what should form the basis of this kind of higher education? And the last one - the methodology of teaching - How to teach it? One 
Table 1.Obligatory minimum of the content for educational program from the Russian Federal standard for speciality "Laser engineering and laser applications".

\begin{tabular}{|c|c|}
\hline Index & Name of disciplines \\
\hline HSE. 00 & $\begin{array}{l}\text { The cycle of humanitarian and economic } \\
\text { disciplines } \ldots \ldots \ldots \ldots \ldots \ldots \ldots \ldots \ldots \ldots \ldots \ldots \ldots\end{array}$ \\
\hline HSE. 01 & $\begin{array}{l}\text { Students choice disciplines and cources.......200 } \\
\text { established by the faculty council }\end{array}$ \\
\hline NS . 00 & 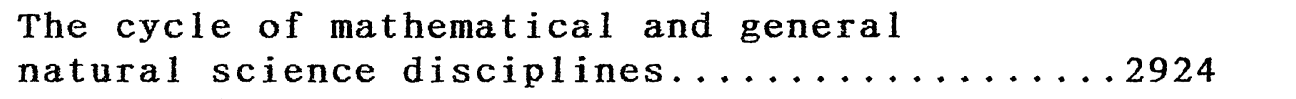 \\
\hline NS. 01 & 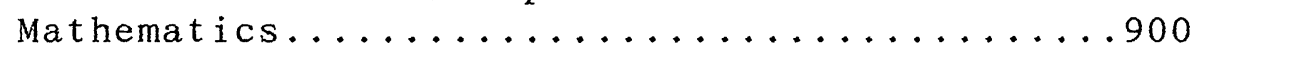 \\
\hline NS. 02 & 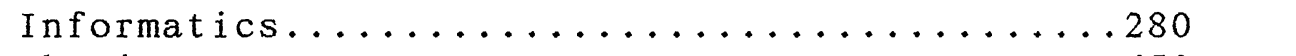 \\
\hline NS.03 & Physics.............................. 650 \\
\hline NS. 04 & 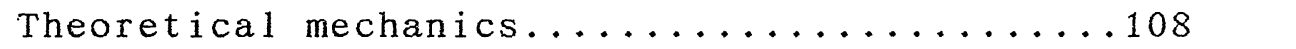 \\
\hline NS. 05 & 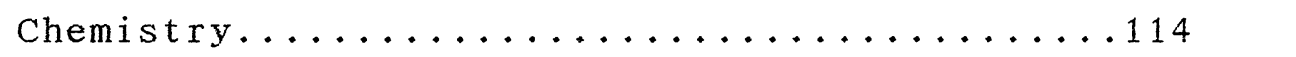 \\
\hline NS. 06 & Ecology........................... \\
\hline NS. 07 & Physical fundamentals of quantum electronics.. 216 \\
\hline NS.08 & $\begin{array}{l}\text { Students choice disciplines and cources } \\
\text { established by the faculty council } \ldots \ldots \ldots 584\end{array}$ \\
\hline GP. 00 & The cycle of general professional disciplines. 1542 \\
\hline GP. 01 & Electronics and computing machinering........360 \\
\hline GP. 02 & $\begin{array}{l}\text { Fundamentals of metrology and optical } \\
\text { physical measuring } \ldots \ldots \ldots \ldots \ldots \ldots \ldots \ldots \ldots\end{array}$ \\
\hline GP.03 & 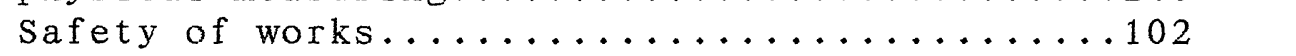 \\
\hline GP. 04 & $\begin{array}{l}\text { Fundamentals of design and optical device } \\
\text { technology } \ldots \ldots \ldots \ldots \ldots \ldots \ldots \ldots \ldots \ldots \ldots \ldots\end{array}$ \\
\hline GP. 05 & $\begin{array}{l}\text { Students choice disciplines and cources } \\
\text { established by the faculty counci } 1 \ldots \ldots \ldots \ldots 70\end{array}$ \\
\hline SP. 00 & The cycle of speciality disciplines. . . . . 1510 \\
\hline SP. 01 & The special parts of optics............440 \\
\hline SP. 02 & $\begin{array}{l}\text { Lasers, } 1 \text { aser engineering and laser } \\
\text { applications } \ldots \ldots \ldots \ldots \ldots \ldots \ldots \ldots \ldots \ldots \ldots \ldots\end{array}$ \\
\hline $\mathrm{SP} .03$ & $\begin{array}{l}\text { Students choice disciplines and cources } \\
\text { established by the faculty council.........800 }\end{array}$ \\
\hline DC. 01 & 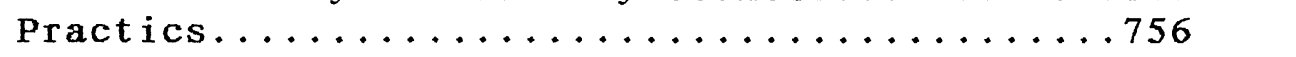 \\
\hline DC. 02 & 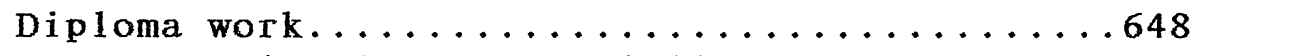 \\
\hline DC. 03 & State examination on speciality $\ldots \ldots \ldots \ldots \ldots 11$ \\
\hline$D C .04$ & $\begin{array}{l}\text { Students choice disciplines and cources } \\
\text { established by the faculty council........970 }\end{array}$ \\
\hline EC. 00 & $\begin{array}{l}\text { Additional kinds of education and optional } \\
\text { courses } \ldots \ldots \ldots \ldots \ldots \ldots \ldots \ldots \ldots \ldots \ldots \ldots \ldots\end{array}$ \\
\hline EC. 01 & Military training (optional course) ......450 \\
\hline
\end{tabular}

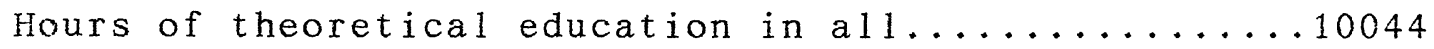


knows that there are no final decisions for these questions. But it is necessary for professionals to continually express some fresh points of view on these topics.

This paper attempts to present our point of view on the problems of the essence and the manner of teaching in LA.

\section{CORE OF SPECIAL EDUCATION IN LASER APPLICATIONS.}

This is the most important question: what should become the core of this kind of education? What should form its basis? This question is most important as further work specialization may tend to very different fields: from industry and production to environmental sciences and medicine.

We believe that focused education in laser applications has tobasedon three whales (fig. 1) briefly: lasers, optics and interaction (laser radiation interaction with matter). It means that during their time of education students should get the necessary knowledge and abilities to answer substantiately and quickly to the next three questions.

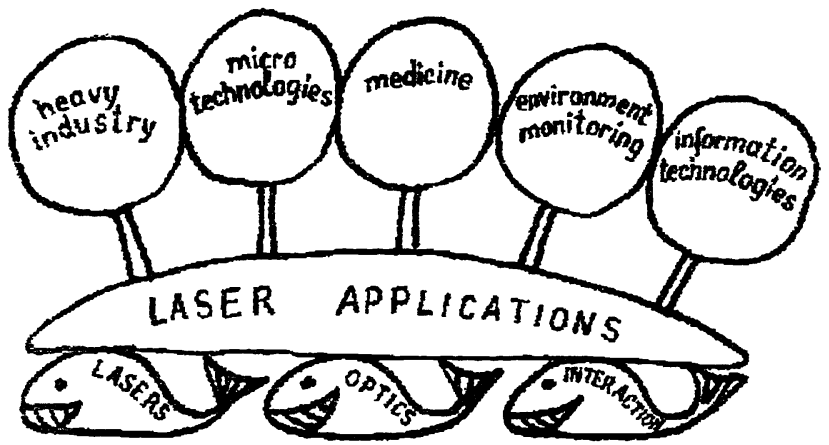

Fig.1. The roots and fruits of university education in laser applications.

1) What type of laser source should be used for the concrete task "A" decision (wavelength, mode of operation continious or pulse repetition, power, pulse duration, coherence, cross-section energy distribution, monochromatism, polarization, etc in consideration with safety demands, reliability, stability and cost? And how to calculate and verify these parameters?

2) What kind of beam-transporting and beam-shaping optical (opto-mechanical, opto-electronic, etc.) systems is necessary for decision of the task "A" ? As the laser beam is a working tool it should be organized in space and time in optimal style. Special optics, opto-mechanical, opto-acoustical, electro-optical and other modulators can provide the necessary time of action. Other optical systems: electro-mechanical, acousto-optical, opto-mechanical scanners 
and controlled diaphragm define the dimensions and shape (cross-section, energy distribution, caustic shape) of laser beam.

At the same time the tasks of transporting of laser energy and collimation, focusing or projection should be solved. Graduate students should know ways of calculation and design, measuring and testing of the main parameters of shaped laser beam.

3) Which kind of interaction (action) of laser radiation with (on) the object matter should be cho-sen to reach the aim of action (resonance - nonresonance, scattering - absorbing, photo - or thermoabsorbing, exitation, heating, hardening, melting, softening, evaporation, decomposition, coagulation, etc.). Solving this question is probably the most important part of task "A" and correspondingly - the most important part of the focused education core for laser applications. This knowledge should give the possibilities to make good-quality estimates and to decrease real expences (because "the good theory is a highly profitable thing!"). This approach was realized in our books (see for example [1]).

This knowledge and abilities are provided by general cources NS.07, SPP.02 $(486 \mathrm{~h})$, by additional disciplines NS.08, GP.05, SP.03 and DC.04 (2824 h), practics $(756 \mathrm{~h})$ and diploma work $(648 \mathrm{~h})$.

\section{GENERAL STRUCTURE OF SPECIAL PROFESSIONAL EDUCATION IN LASER APPLICATIONS AT LASER TECHNOLOGIES DEPARTMENT OF IFMO.}

Structure of courses SP.03, proposed by the physical-engineering faculty in LA and provided by the LTD is presented in Table 2. Five basic and three optional elective courses are given every year.

Certainly each subject, i.e. industrial technologies, medicine, environmental studies is supported by all basic courses. They have many common issues in interaction of radiation with matter, in optics, laser equipment and processes control.

Students have a laboratory training in every subject. Some of them are located in the premises of production facilities (technology) of the institute (environment) and clinics (medicine).

Theoretical seminars are held under items $1,2,3$. There by students acquire practical skills in quantitative estimates of laser-matter interaction models and substantiation of processes, devices and instruments.

Basic sections of SP.03 courses was given earlier [2] and as classical for this speciality disciplines have no substantial alterations. Elective courses E.5, E.6, E.7 programms (tables $3,4,5)$ are presented below. 
Table 2. Structure of special professional cources at LTD (SP.03).
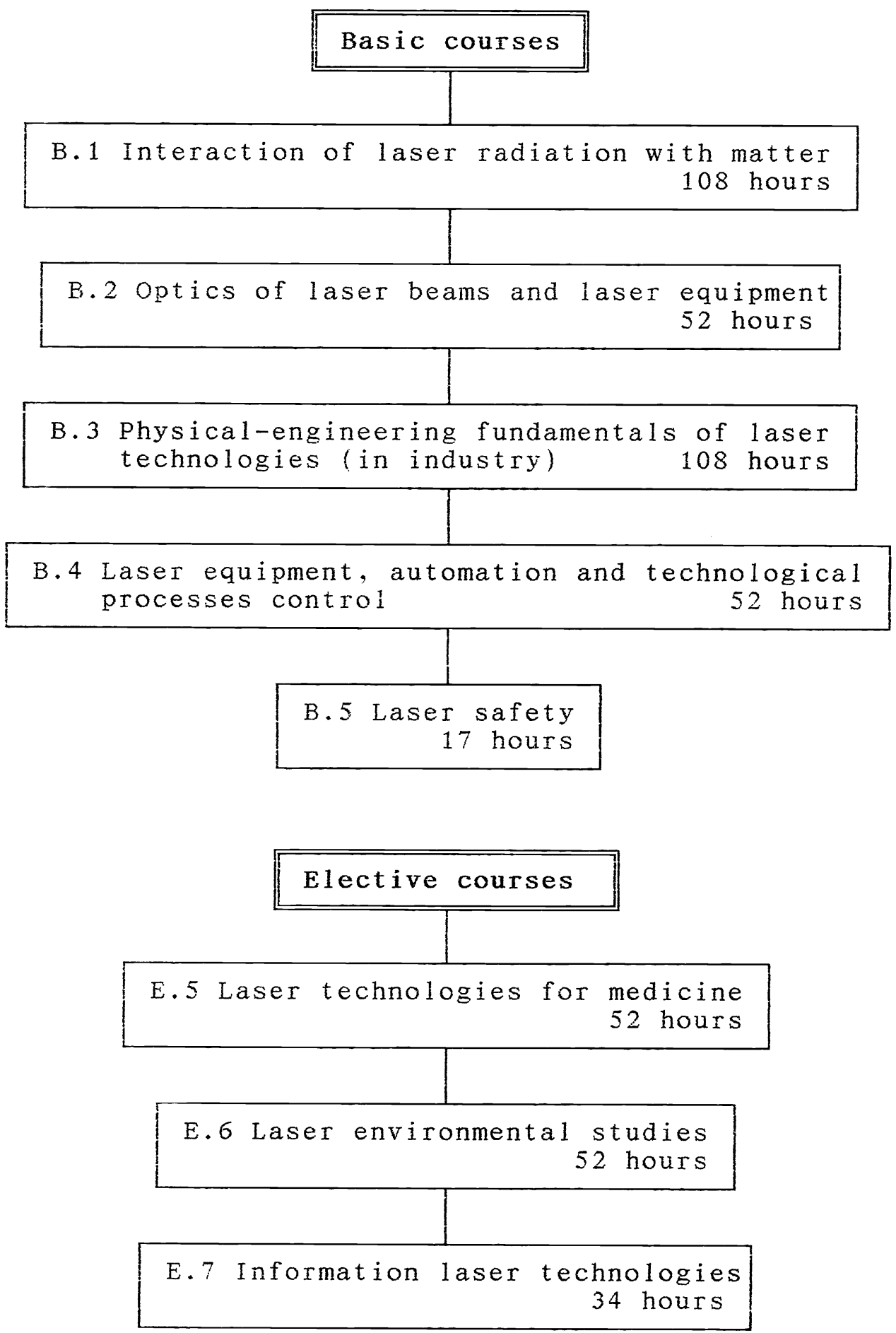
Table 3.Basic sections of the course E.5

"LASER TECHNOLOGIES FOR CLINICAL MEDICINE".

\section{Laser Radiation Biological Effects}
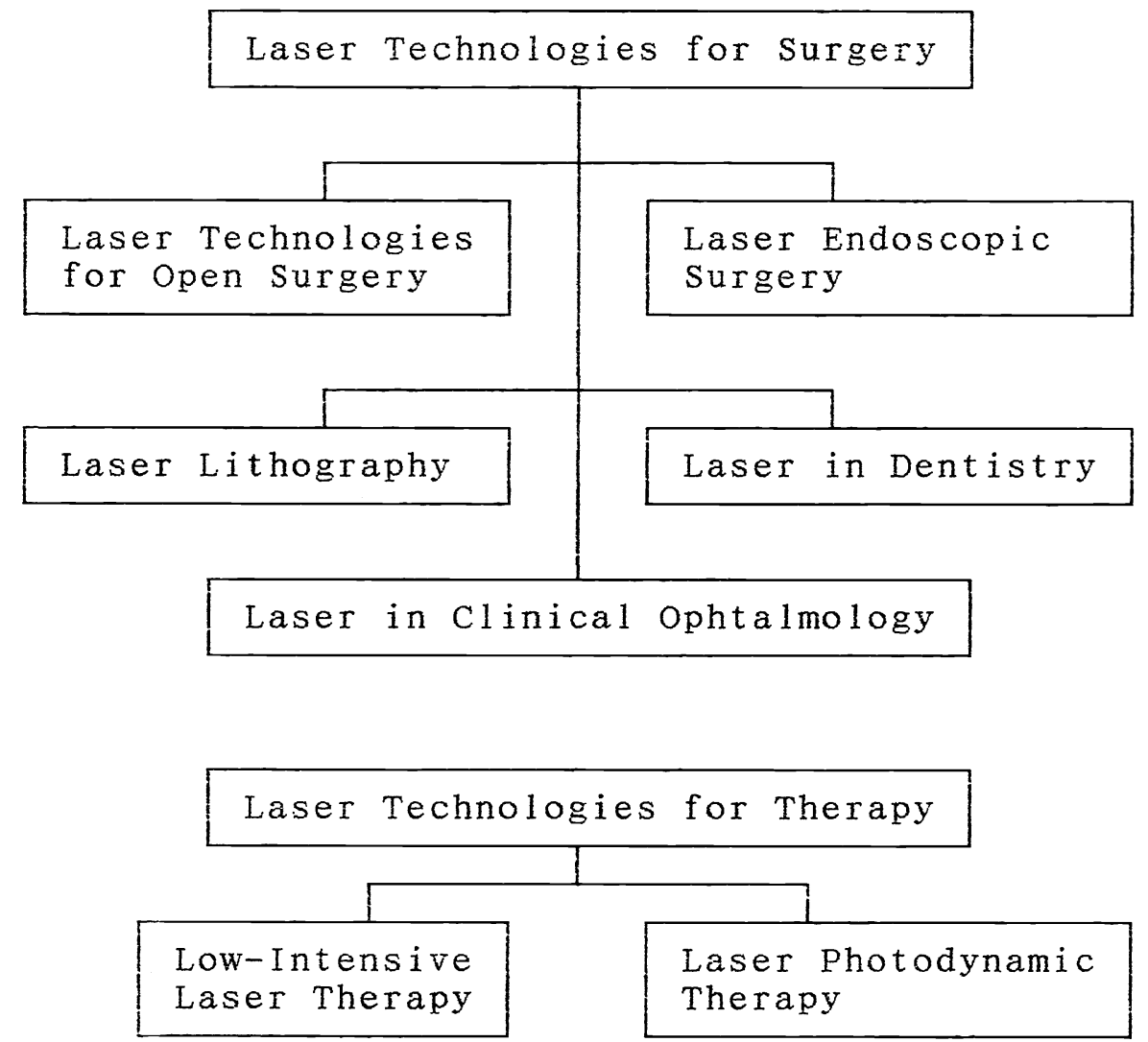

Safety Requirements for Laser Medical Applications 
Table 4. Basic sections of the course E.6

"OPTICAL METHODS IN ENVIRONMENTAL MONITORING".

Part 1. Physical background of optical methods application to ecological problems Absorptive spectroscopy. Refractometry.

2. Optical media with continuous variations of parameters. Light propagation in refractive turbulence.

3. Molecular scattering. Raman scattering.

4. Light scattering by discrete unhomogenities. Air- and hydrosoles.

5. Radiative transfer theory. Optical characteristics of the atmosphere and the ocean.

6. Fluorescence. Fluorescence spectra of atmospheric and ocean constituents.

Part 2. Laser-based methods and instruments for environmental monitoring.

7. Various laser sources. Generated
wavelengths Detectors of laser radiation.
8. Lidar equation
1aser-pulsed sounding. Back-scattering characteristics.
9. Differential absorption and Raman scattering lidars
for remote sensing and pollution monitoring of the
atmosphere.
10. Laser bathymetry and lidar sounding of near-surface
ocean waters. Data processing and inverse problems
11. Remote detection of oil spots on water surface with
airborne lidars. methods. Coherent lidar technology;
inter-cavity spectrometric techniques.

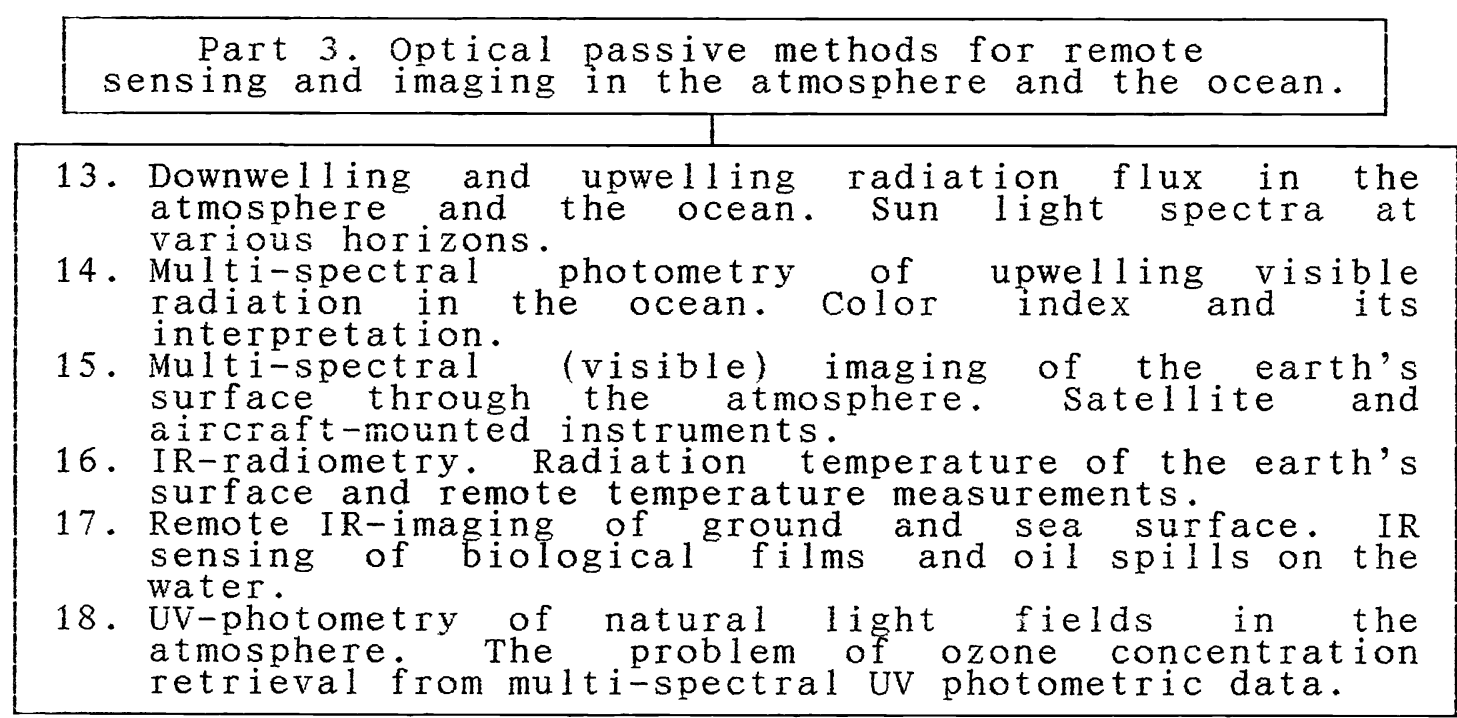


Table 5. Basic sections of the course E.7

"INFORMATION LASER TECHNOLOGIES".

Fundamental principles - general for optical processing of information
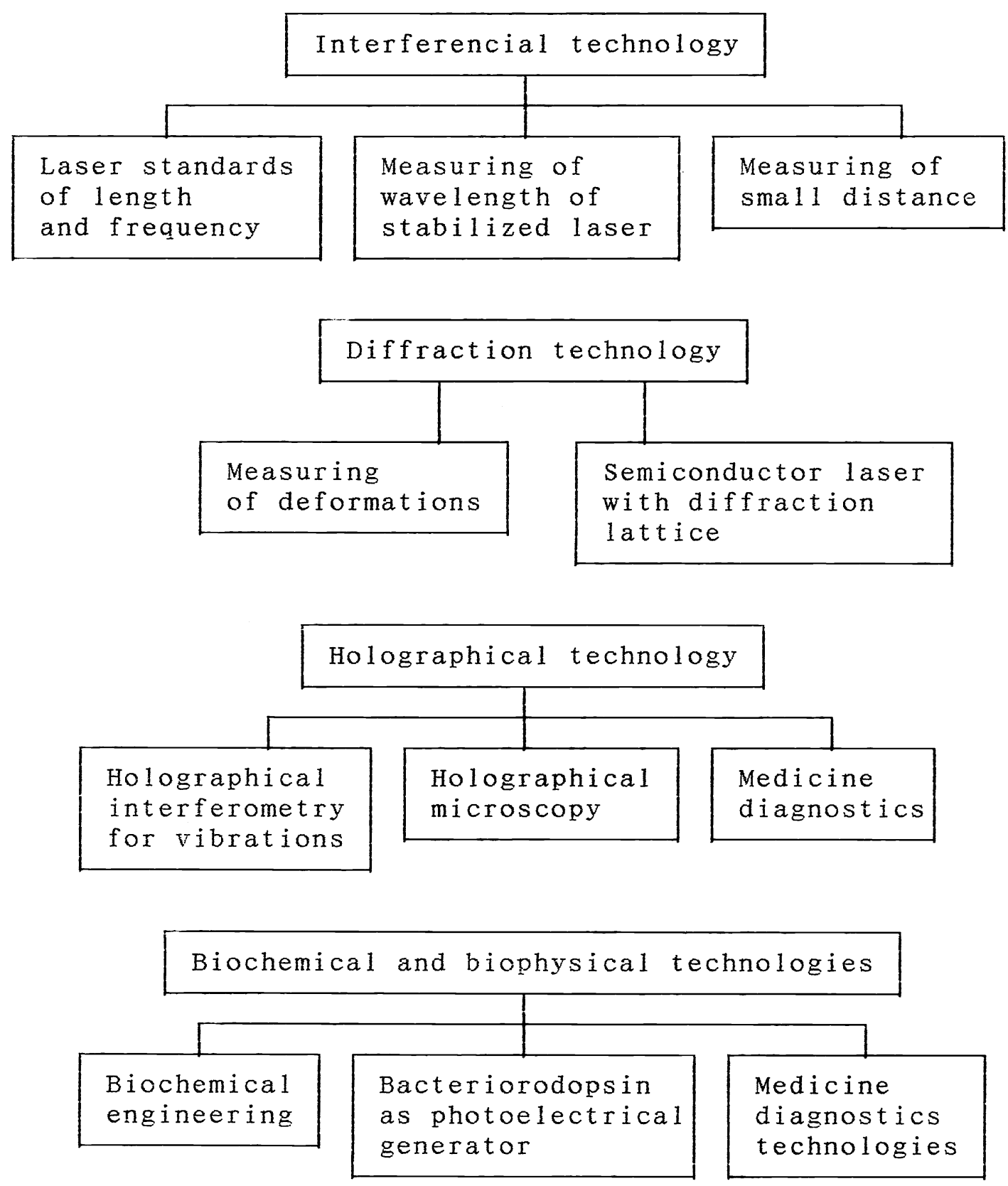


\title{
4.HOW TO TEACH LASER APPLICATIONS.
}

There are no special means to teach LA - it is a common question. let me discuss a little bit about this topic.

It is necessary for students to be very motivated for hard learning. In most cases we have deals with normal young people who have only one life for learning, for living, for sport, for love, for art etc. So we should have some special ways to attract them to our subject. First of all, it is necessary to have good science labs, where students can watch and take part in the real process of using of the knowledges. It stimulates them to acquire a new knowledge.

A second problem primarly for lectures - students attention concentration. We 11 known joke is that the normal student auditorium consists of the following audience (Fig. 2), but I will interprete it form optical point-of-view: complete reflection, complete transparance, complete absorbance, refraction and partial absorbance (optimal type of perception) and persons out of sound (at dead zone seatting). Probably this is a result of a passive education. Most of all we are interested in providing students with not passive (dead) but active (1iving) knowledge.

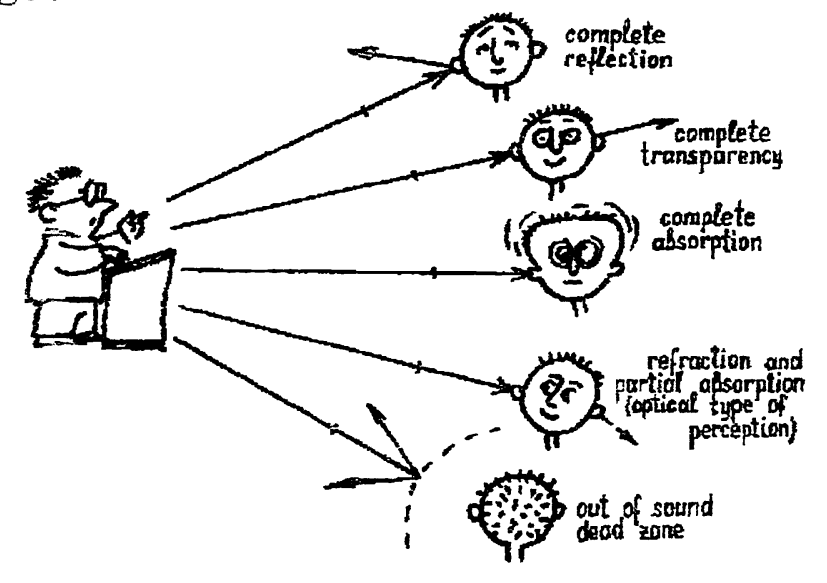

Fig.2. The students auditorium personnel from the lecturer in optic point-of-view.

\begin{abstract}
So we are required to give a number of tasks for using of knowledge (better as versions of real projects, investigations etc). In this case the task deciding is the purpose, and the knowledge is higher purpose. From psychological point-of-view it permit us to overcome the antisuggestive barrier of persons.

That is why we widely use the exercises at this topic, and approximately 60-100 hometasks should be decided per last graduate year. Some examples of them are given at Appendix 1 .
\end{abstract}




\section{ACKNOWLEDGMENTS}

Author is thankful to colleguaes Dr. A.I.Serbin, Dr. Ju.I.Kopelevich, Dr. E.A.Shakhno, Dr. G.D.Shandybina, Dr. Ju.D.Berezin and dipl. engineers D.L.Goobanov, A.K.Kromin and S.M.Sarnakov for helpful discussion and assistance in preparing of this paper.

\section{APPENDIX 1.}

Hometask example. Define the threshold intensities of $\mathrm{CO}_{2}-1$ aser radiation for cutting of the number of constructional materials and biological tissues depending on laser beam scanning speed (slow or fast moving source).

\section{REFERENCES .}

1. S.M.Metev, V.P.Veiko. Laser-assisted microtechnology. Heidelberg, Sppringer, 1994.

2. V.P.Veiko, M.N.Libenson. Higher education in laser applications. Proceeding of SPIE, vol. 1603, Education in Optics, p. 222-231, 1991 . 